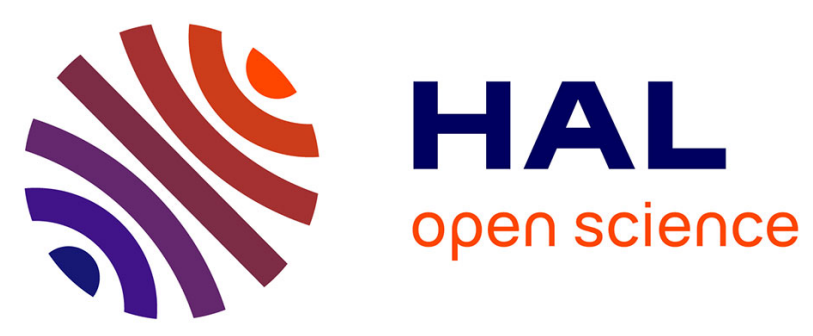

\title{
The read-out electronics of the AMS prototype RICH detector
}

\author{
L. Gallin-Martel, P. Aguayo de Hoyos, L. Eraud, J. Marin Munoz, G. \\ Martinez Botella, J. Pouxe
}

\section{- To cite this version:}

L. Gallin-Martel, P. Aguayo de Hoyos, L. Eraud, J. Marin Munoz, G. Martinez Botella, et al.. The read-out electronics of the AMS prototype RICH detector. International Conference on New Developments in Photodetection 3, Jun 2002, Beaune, France. pp.273-275. in2p3-00012483

HAL Id: in2p3-00012483

https://hal.in2p3.fr/in2p3-00012483

Submitted on 16 Jun 2003

HAL is a multi-disciplinary open access archive for the deposit and dissemination of scientific research documents, whether they are published or not. The documents may come from teaching and research institutions in France or abroad, or from public or private research centers.
L'archive ouverte pluridisciplinaire HAL, est destinée au dépôt et à la diffusion de documents scientifiques de niveau recherche, publiés ou non, émanant des établissements d'enseignement et de recherche français ou étrangers, des laboratoires publics ou privés. 


\title{
The read out electronics of the AMS prototype RICH detector
}

\author{
L. Gallin-Martel ${ }^{\mathrm{a}^{*}}$, P.Aguayo de Hoyos ${ }^{\mathrm{b}}$, L.Eraud ${ }^{\mathrm{a}}$, J. Marin Muñoz ${ }^{\mathrm{b}}$, \\ G. Martinez Botella ${ }^{\mathrm{b}}$, J.Pouxe $\mathrm{a}^{\mathrm{a}}$ \\ ${ }^{a}$ Institut des Sciences Nucléaires,53 Avenue des Martyrs, F-38026 Grenoble Cedex, France
}

${ }^{b}$ Centro de Investigaciones Energéticas Medioamtientales y Tecnológicas, Avda Complutense, 22, 28040 Madrid, Spain

\begin{abstract}
A Ring Imaging Cherenkov (RICH) counter dedicated to the AMS experiment is under development. An integrated circuit has been designed with the Austriamicrosystems 0.6 Pm CMOS technology to process the signals of the 16 anode PMTs used in the photon detection. To improve the detector compactness, the read out electronics is placed very close to the PMTs. This lead to the design of a detection cell that comprises : a light guide, a PMT, a high voltage divider, an analog front end chip and an analog to digital converter. The analog front-end chips were extensively and successfully tested in a laboratory environment, 96 of them are now mounted on the RICH prototype. Tests with cosmic rays have started. Ion beam tests are planed in a near future. (C) 2002 Elsevier Science. All rights reserved
\end{abstract}

Keywords : RICH detector; Read-out electronics; AMS experiment

\section{Introduction}

A first integrated circuit was designed in 1996 [1] to process the signals from the PMTs of the Ring Imaging Cherenkov (RICH) counter for the AMS experiment [2]. A complete prototype, including trigger and tracker detectors as well as DAQ system, was assembled [3] and tested with cosmic rays and with a light ion beam [4]. In this preliminary version, single anode PMTs were used and the 3 channel front end chip was processing groups of 3 PMTs. In order to improve the spatial resolution of the detector (by reducing the pixel size), 16-anode PMTs (R7600M16 from Hamamatsu [5]) were chosen to equip the upgraded version of the prototype. A new 16 channel chip was designed using the AMS 0.6 Pm CMOS

\footnotetext{
* Corresponding author. Tel.: +33-4-76-28-40-84; fax: +33-4-76-28-40-04; e-mail: L.Gallin-Martel@isn.in2p3.fr.
} 
technology (Austriamicrosystems) [6]. This chip is part of the new detection cell of the present version of the RICH prototype.

\section{Front end chip architecture}

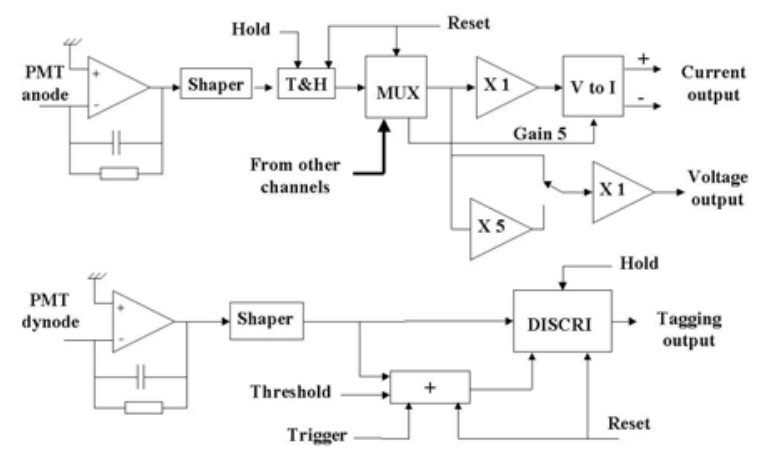

Fig. 1. The block diagram of the chip.

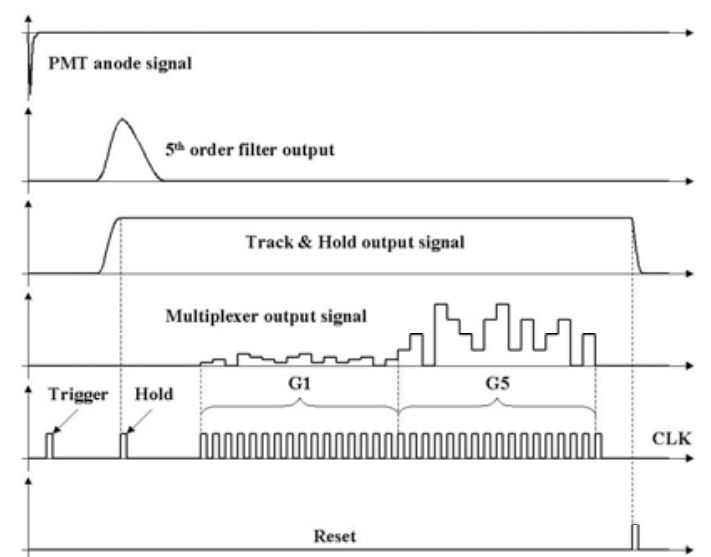

Fig. 2. The anode channel chronograms.

The 16 identical channels of the low power front end chip are processed by a multiplexing system. Each channel performs the charge measurement of the corresponding anode signal using a spectroscopy amplifier. The height of each shaper output pulse is memorized using a track and hold circuit. The 16 signals are then fed into a multiplexer. A gain 5 amplifier stage associated with the multiplexing system allows two ranges of amplification. The chip provides an output voltage and a differential output current.

The dynode channel of the chip, also based on a spectroscopy amplifier, processes this PMT signal (Fig. 1). The DC level of the chain is memorized and added to an external threshold. The amplified dynode pulse is then compared to this corrected threshold. This auto-zero function allows the offset of the spectroscopy chain to be cancelled. On the prototype currently under test the dynode channel of the chip is not used and the data reduction is performed, on line, by the digital read out electronics. The analog and digital memories are cleared by a RESET signal at the end of the digitalization. The 16 anode and dynode channels are controlled by a single CLK signal (Fig. 2).

The other typical features of the (QFP44 packaged) chip are :

* integral non linearity (INL) : $< \pm 0.3 \%$,

* noise: $<0.02$ photo-electron RMS,

$*$ power supply : $+3 \mathrm{~V},-2 \mathrm{~V}$,

* power consumption : $13 \mathrm{~mW}$.

\section{Light detection cell}

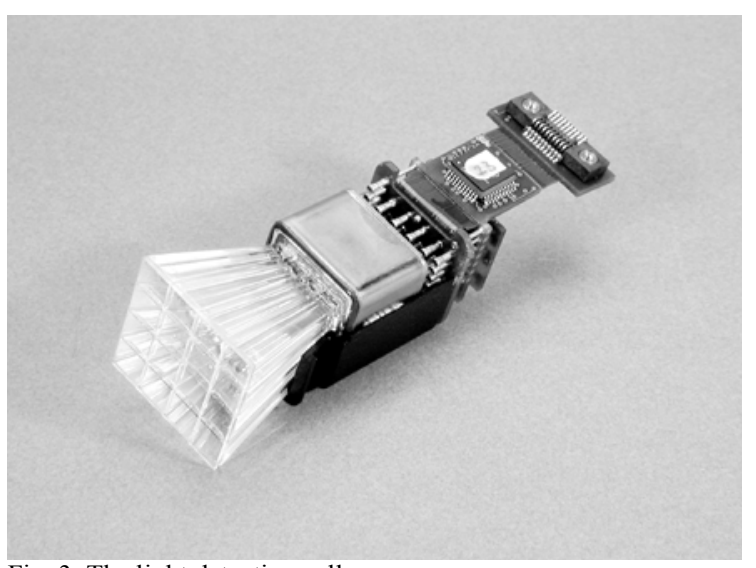

Fig. 3. The light detection cell.

Around 700 PMTs will equip the AMS RICH detector. One of the main requirement in the design of the front end electronics is the compactness. A light detection cell comprises :

* a 16 pixel light guide in front of each PMT,

* a high voltage divider, 
* the analog front end chip previously described,

* an analog to digital converter.

The front end chip is controlled by two signals (CLK and RESET). Its output signal is digitized by a low power, serial output ADC (AD7476 from Analog Devices).

\section{Digital read out electronics and event formatting}

The detection cells are arranged inside a matrix and are connected to the read out electronics using flexible printed circuits boards (FPCB). The read out electronics consists in three DSP based boards processing three FPCBs each. On a trigger signal occurrence the control sequence for the analog front end chips and the ADCs is generated by a FPGA circuit located on each DSP board. The ADC data are then processed by the DSPs (pedestal analysis and subtraction, data reduction) and finally stored in the memory of each board. Then, the VME data acquisition is performed. Only a few cells are hit for each event, so the ADCs mainly provide the pedestal values of the analog front end chip. The DSP takes advantage of this by computing on line the mean value and the sigma of the pedestal distribution for each channel. This permits to set the digital thresholds used in the data reduction algorithm.

\section{Overview of the prototype set up}

The RICH prototype includes 96 detection cells located with the read out electronics in a vacuum chamber that contains a layer of radiator material (Silica aerogel) where Cherenkov light is generated. Outside the chamber three scintillators coupled to three PMTs provide the experimental trigger. The trajectory of incident particles is reconstructed using three MWPCs (Multi Wire Proportional Chambers). The signals from the trigger and the tracker detectors are processed in a CAMAC crate and then the digital data are read by a VME crate. This crate also read the memory of the front end electronics.

\section{Conclusion}

A 16 channel chip has been designed in AMS 0.6 $\mu \mathrm{m}$ CMOS technology. The upgraded version of the $\mathrm{RICH}$ prototype, currently in test has been equipped with 96 of these chips. They have been extensively and successfully tested in a laboratory environment using a dedicated test bench [7]. The RICH prototype is now tested with cosmic rays to check the reconstruction software. An ion beam test is also foreseen by the end of year 2002 to investigate the response of the counter to ions with $\mathrm{Z}<25$.

\section{References}

[1] L. Gallin-Martel, J. Pouxe, O. Rossetto, "A BiCMOS integrated charge to amplitude converter”, IEEE 1996 Nuclear Science Symposium and Medical Imaging Conference, Anaheim, $3^{\text {rd }}-10^{\text {th }}$ November 1996.

[2] B. Alpat et al, Nuclear Physics B (Proc. Supl.) 54B (1997) 335

[3] L. Gallin-Martel, J. Pouxe, O. Rossetto, P. Stassi, Nucl. Inst. and Meth. A 433, (1999,) 444.

[4] T. Thuillier, F. Malek et al, "Experimental study of a proximity Cherenkov counter prototype for the AMS experiment", ISN report 01-89, January 2002.

[5] More details on http://www.hamamatsu.fr/

[6] L. Gallin-Martel, J. Pouxe, O. Rossetto, M. Yamouni, “A 16 channel analog integrated circuit for PMT pulses processing", ISN report 01-49, 2001.

[7] L. Eraud, L. Gallin-Martel, "A test bench for the Front End Chip of the AMS RICH”, ISN report 01-79, September 2001. 